\title{
National Baseline Survey on Monitoring and Evaluation of Blood Screening Systems in Pakistan
}

Hasan Abbas Zaheer* and Usman Waheed

Safe Blood Transfusion Programme, Ministry of National Health Services, Government of Pakistan, Pakistan

*Corresponding author: Hasan Abbas Zaheer, Safe Blood Transfusion Programme, Ministry of National Health Services, Government of Pakistan, Pakistan, Tel: 92-333-5123814; E-mail: hazaheer@gmail.com

Received date: Feb 12, 2015, Accepted date: Apr 02, 2015, Publication date: Apr 06, 2015

Copyright: $\odot 2015$ Zaheer HA, et al. This is an open-access article distributed under the terms of the Creative Commons Attribution License, which permits unrestricted use, distribution, and reproduction in any medium, provided the original author and source are credited.

\begin{abstract}
The objective of the national survey was to analyze all aspects of the blood screening system in blood banks in Pakistan. The survey tools were based on WHO evaluation framework for assessment, monitoring and evaluation of blood screening systems adapted for application in Pakistan. The survey documented quantitative (sample size 170 blood centers, both in public and private sector in all the four provinces and Azad Jammu \& Kashmir, Gilgit Baltistan, and Federally Administrated Tribal Areas) as well as qualitative aspects to the extent possible. A structured pretested questionnaire was used to collect the data. Statistical analyses were carried out by simple descriptive statistics using MS Excel 2010. The survey documented quantitative (sample size 170 blood centers, both in public and private sector in all the four provinces and AJK, GB, and FATA) and qualitative aspects to the extent possible. The findings of the survey provided a comprehensive situation analysis of the state of the blood screening system in the country.
\end{abstract}

Keywords: Blood banks; Transfusion; Infections; Blood screening; Quality control; Pakistan

\section{Introduction}

With a population exceeding 180 million, Pakistan is a developing country with under developed transfusing services. The total annual blood collection in Pakistan is estimated to be 3 million units [1]. Blood donors in Pakistan are mostly replacement/family donors influenced by local, social, and cultural traditions that increase the risks of transfusion transmitted infections [2]. The seroprevalence of $\mathrm{HBV}$ in blood donors varies from $1.46 \%$ to $8.4 \%$ while for $\mathrm{HCV}$, it is between 0.27 to $8.68 \%$ [3]. The prevalence of malaria and syphilis have been documented as $1.2 \%$ and $0.89 \%$ respectively in the blood donors [2]. Currently hospital blood banks cover the entire vein-to-vein process including blood collection, component preparation, blood screening, and compatibility testing. A 2008 study pointed out several gaps in the blood screening system including non-availability of testing guidelines, non-adherence to testing protocols, use of substandard test kits, lack of training opportunities, non-availability of SOPs, and lack of occupational health and safety mechanisms [4].

The key issues in the blood transfusion sector of Pakistan are lack of governance and effective regulation. It was only in the late 1990s through early 2000s that Pakistan passed Blood Safety Laws in all the federating units [5]. At present, the transfusion services are provided through a fragmented blood transfusion system in which all the blood centers function in isolation with little interaction and limited regulatory control. The policy decision made in 2008 in order to establish a 'nationally coordinated' blood transfusion system faced challenges in 2011 due to the devolution of the health sector [6]. Nonetheless, a nationally coordinated blood transfusion programme exists in the country both at the federal and provincial levels since 2010 and is reaching completion of its initial phase. Universal coverage is the long term aim of the project. The new Programme at the national and provincial levels is steering the development of transfusion services on the lines of the internationally recommended model. The objective of this initiative is to provide centrally coordinated blood transfusion services at affordable costs nationwide. Through the Programme, the systems reforms are being introduced through the development of blood donor policy, SOPs, guidelines, manuals etc., in addition to the development of a new physical infrastructure.

The available data on all aspects of blood transfusion including blood donations, transfusion and screening is incomplete and scattered and cannot be relied on to form any basis of designing interventions to improve the blood transfusion system in the country. Since a comprehensive national baseline survey on blood transfusion has never been conducted, so the available information is fragmented and does not present a complete picture on the blood transfusion system in the country. As part of the efforts of the Government of Pakistan to establish a national blood transfusion system based on voluntary non-remunerated donation and with every aspect governed by quality management, an analysis of the screening processes in the existing blood transfusion situation was performed.

\section{Material and Methods}

This was a cross-sectional descriptive study and multi-stage random cluster sampling approach was followed. 170 blood banks/centers were surveyed from all the four provinces of Pakistan including Islamabad Capital Territory, Azad Jammu \& Kashmir, and Gilgit Baltistan. All surveyed facilities were performing transfusion services which are hospital based, public or private, and are located in both urban and rural areas throughout the country. The evaluation and baseline survey tool was pre-tested and shared with all the 170 blood centers surveyed and the data collected from all the centres was analyzed. Each question included multiple options or statements under the different headings such as regulatory framework, organization and management, 
Page 2 of 5

procurement, quality assurance system, management, screening processes, technical and financial capacity, and physical infrastructure. The blood centres were informed about the nature and general objectives of the study. The survey documented quantitative and qualitative aspects to the extent possible. The survey tool was based on WHO evaluation framework for assessment, monitoring and evaluation of blood screening systems adapted for application in Pakistan. It was made sure that all questionnaires were filled by the Incharge/Pathologist of the blood center. The field work of the survey was conducted between July 2012 and January 2013 and the data entry and analysis process was completed by May 2013. Statistical analyses were carried out by simple descriptive statistics using MS Excel 2010.
The study was approved by the Institutional Review Board of the Safe Blood Transfusion Programme.

\section{Results}

The 170 surveyed blood centers served a total of 1,167 hospitals both in the public as well as private sector. Almost $70 \%$ of the surveyed blood centers were in the two most populous provinces of Punjab and Sindh. The survey findings reflected a high percentage of NGO run blood centers. In the Sindh province, $52 \%$ as compared to $31 \%$ in Punjab were run by NGOs to meet the growing demands of the transfusion needs of the population (Figure 1).



Figure 1: Province wise distribution of surveyed blood centers.

\section{The Survey Findings were Analyzed Under the Following Headings}

\section{Organization and Management}

Of the 170 blood centers surveyed, 115 were hospital based blood centers, both in the public and private sector. Of the 115, 108 (94\%) blood centers were part of the pathology department of the respective hospitals. Written job descriptions of the staff were available in almost $93 \%$ of the blood centers surveyed whereas, about $70 \%$ of the blood centers designated specific staff member for quality management.

\section{Regulatory framework}

The findings of the survey indicated that the blood transfusion regulatory framework was inconsistent in different provinces. Of all, the Sindh Province had a fully functional blood transfusion authority which has a data base of all registered as well as unregistered blood centers in the province. Of 170 blood centers surveyed, a total of 80 were granted licenses and 26 blood centers were inspected at least once. So, $62 \%$ of the blood centers were covered to some extent by the respective Blood Transfusion Authorities.

\section{Physical infrastructure}

The physical infrastructure for various sections of blood transfusion process were properly identified and segregated in $84 \%(n=143)$ of the blood centers surveyed. All 170 blood centers surveyed had power and water supply connections but $75 \%$ of the blood centers faced power cuts in the range of 5-12 hours daily. Backup generation facilities were available in $70 \%$ of the blood centers which were deemed to be adequate in order to maintain the stored products at recommended temperatures. Dedicated vehicles were available in the private sector stand-alone blood banks and blood transfusion centers, while in the hospital blood banks, vehicles from the motor pool were shared. Overall, communication facilities were better and/or functional in private sector blood centers.

\section{Management, technical and financial capacity}

In the absence of Management Information System, both in the public and private sector, data management was not accorded priority in almost half of the blood centers surveyed. Almost $85 \%$ of the blood centers surveyed had a system of stock controls which ensured continuous and uninterrupted supply of critical consumable items. 
Page 3 of 5

The survey findings indicated limited scale and scope of technical support to blood centers. A total of 26 centers received any external financial support from government and/or private sector donors. Almost all public sector blood centers received funds as part of the overall budgets allocated to public hospitals by the provincial and federal governments. The technical staff of the blood centers was neither consulted nor was it part of the budget allocation process in the public sector. Their role was limited to identify the procurement requirements for consumable items and equipment. $66 \%$ of the blood centers had a policy of vaccination of the blood bank staff against Hepatitis B with only $32 \%$ maintaining any record of its staff for any exposure to transfusion transmissible infections.

\section{Quality assurance system}

Only 99 (58\%) blood centers had a quality assurance policy. The situation was worse in public sector blood centers where majority (55\%) of the blood centers lacked an internal quality audit system. The lack of internal quality audit system had a direct bearing on the accuracy and reproducibility of tests. Standard Operating Procedures (SOPs) were available in most $(70 \%)$ of the blood centers. How far were the SOPs adhered to actual practice was subject to the effectiveness of the internal management and quality audit system. Except for waste management record, over $90 \%$ of the blood centers surveyed maintained some form of records. About $50 \%$ blood centers had an Algorithm for screening donated blood for transfusion transmissible infections. Out of this, about $70 \%$ of the private sector and $39 \%$ of public sector blood centers use algorithm for Transmitted Transfusion Infections (TTIs) prevention. As accreditation of blood centers was not mandatory in Pakistan, none of the 170 blood centers surveyed were accredited. In the public sector blood centers, 59\% of the centers in comparison to $56 \%$ in the private sector evaluate consumable supplies before procurement. Validation is conducted in only $48 \%$ of the public sector blood centers, not in the private sector.

\section{Screening processes}

Operations and processes of blood centers including screening strategies were; irregular, unsafe and unregulated in the majority of the blood centers. Almost $43 \%$ of the blood centers had no internal quality audit system and none of the blood centers surveyed had any external quality control system. About $69 \%(n=117)$ of the total surveyed blood centers stored test kits and samples in temperature monitored equipment (TME). 67\% in the public sector centers and $89 \%$ in the private sector had TME. All blood centres screened for $\mathrm{HBV}, \mathrm{HCV}$ and HIV but only $3 \%$ of them screen for syphilis. The malaria screening was performed in less than $50 \%$ of the blood centres. TTIs screening was conducted either manually or through automated systems. Almost $73 \%$ of the surveyed blood centers performed some form of internal quality control (IQC) for TTI screening. In the private sector, $18 \%$ had no IQC in comparison to $32 \%$ in the public sector.

\section{Procurements}

In the public sector blood centers, $95 \%$ of the equipment was purchased centrally by the health departments in comparison to the private sector where $80 \%$ of the equipment was procured locally. The procurement process involved little input of the technical staff. Almost $92 \%$ of the surveyed blood centers $(n=157)$ had a programme or system for equipment maintenance. The situation regarding validation of the supplies was more dismal in the private sector where hardly any center validates their supplies while in the public sector about $48 \%$ of the centers validated the supplies.

\section{Discussion}

The Blood Transfusion Services in Pakistan are based on provincial structures guided by the Blood Safety Acts introduced between 1997 and 2004 in all provinces including the state of Azad Jammu \& Kashmir. Services are provided by public or private hospital blood banks or stand-alone facilities. There is generally no separation between manufacturing units (Blood Centres) and ordering units (Blood Banks), which has an impact on the organization of services.

The proportionate distribution of blood centers surveyed reflects a bias towards the public sector hospital based blood transfusion facilities (63\%) which were more readily accessible and responsive to the survey. The involvement of the private sector in the blood transfusion services is a relatively late phenomenon in

Pakistan. The private sector contributes through blood centers that are hospital based as well as stand-alone blood banks and blood transfusion centers. In the private sector, usually the larger hospitals have their own blood banks which cater to the needs of the indoor patients. Many private sector hospitals rely on the private stand -alone blood banks and the blood transfusion centers which provide services to the general public at large. Another factor that encouraged the growth of private sector blood transfusion centers is the high number, around 100,000 transfusion dependent thalassemia patients, who have poor access to regular blood transfusion services in the public sector. The thalassemia patients are not hospitalized and yet they require regular blood transfusions. The private sector blood transfusion centers primarily serve the thalassemia patients through the blood centers of the respective blood transfusion centers.

None of the blood centers surveyed have outsourced or delegated any of its functions to any other organization. All blood centers surveyed function as complete

units covering all aspects of blood transfusion work including; mobilizing and recruiting blood donors, blood collection, testing, screening, component preparation, and storage all under one roof. In the blood transfusion centers, blood transfusion is also administered to patients in addition to the above mentioned functions.

The high figure of blood banks associated with pathology department was indicative that transfusion medicine was still not considered a specialty on its own nor it has accorded the priority in view of the public health implications of safe blood transfusion. Although majority of the hospital based blood centers function as part of the pathology department, yet $90 \%$ of these blood centers had their own dedicated staff which clearly indicated that transfusion medicine was an independent specialty and should not be part of the overall organizational set up of the pathology department.

Secondary data indicated that financial support from national sources was restricted solely to the private sector blood banks ranging from individuals/philanthropists to organizations such as Bait-ulMaal. The blood centers in the private sector also generated resources by charging patients.

The situation regarding regulatory framework is reflective of the absence or not fully functional status of the blood transfusion regulatory authorities in different provinces. The finding does not imply that the remaining blood centers are providing illegal or 
unauthorized services. The low number of licensed blood transfusion centers is also a reflection of the limited functional capacity of the blood regulating authorities in most provinces and regions of the country which points to a critical gap in blood safety. In Sindh province, the regulatory system is most organized and functional. In Punjab province, the blood transfusion authority has been notified in the process of assuming greater functional status. In KPK province, the blood transfusion regulatory function remains part of the Health Regulatory Authority (HRA) which includes a section to regulate blood transfusion services. In Baluchistan province, the Blood Regulatory Authority has been notified and is in the early stages of formation. In $\mathrm{AJK}$, the blood transfusion regulatory body has been notified and is functional. In ICT, the blood transfusion authority was functional and due to devolution process, a new management structure is being developed. In FATA and GB, the blood transfusion regulatory authorities are yet to be notified.

The lack of readily available information on budget allocations was the primary reason for not sharing budget information during the survey. Conclusions drawn from observations by the technical staff of the blood centers indicated that there was a general reluctance to share budget related information both in the public and private sector. Even the finance department in public sector hospitals were reluctant to share information about budgetary allocations with the technical staff of blood centers. Discussions revealed that the technical staff of the blood centers was neither consulted nor made part of the budget allocation process in both the public and private sector. The technical staffs' role was limited to identifying the procurement requirements for consumable items.

Regarding the quality assurance system, the survey findings indicated that public and private sector blood centers accord low priority to implementation of quality assurance policies. Lack of proper handling of the contaminated blood center waste including sharp materials is a potent risk factor in the spread of infections particularly Hepatitis B and C infections. In addition, improper disposal of the contaminated blood bank waste also contributes to the reuse and recycling of the disposable material which is an important source of spread of hepatitis infections in Pakistan [7]. In the absence of any national guidelines for the evaluation and validation of consumable supplies, the risk of procuring poor quality consumables is high.

The WHO recommends mandatory screening for five TTI's namely; HIV, Hepatitis B \& C, Syphilis, and Malaria [8]. The findings of the survey indicate that screening is done for only three TTIs (HIV, Hepatitis B \& C) in all types of blood centers while malaria and syphilis testing is limited. The quality and performance of kits is compromised by frequent interruptions in power supply. The use of screening kits not stored at recommended temperatures can also contribute to transfusion of infections through transfusions. WHO do not recommend utilizing rapid test kits in blood banks with substantial number of donations but many centres have reported the use of rapid test kits [9].

As can be seen from the results, there is no regulatory control over the import of the consumable supplies. The lack of import regulatory controls coupled with low cost as the overriding procurement factor results in the availability of poor and sub-standard cheap options in the market. As a result, poor quality kits are procured without quality evaluation and validation either locally or at the national level. The situation regarding validation of the supplies is more dismal in the private sector where hardly any center validates the supplies while in the public sector about half the centers validate the supplies.

There are certain limitations that must be looked in before interpreting the results of our study, e.g. selection bias, etc.

\section{Conclusion}

The situation demands an overhaul of the whole process of blood transfusions both in government and private healthcare systems without any further delay. The findings of the survey underscore the need for Transfusion Medicine and Blood Banking to be recognized as an entity separate from Pathology, with its own specialists and their career structure. Licensing of the blood centers should be made mandatory and regulatory arm of the blood transfusion services must be strengthened with both human and financial resources. The national baseline survey and the analysis of the findings of the survey are expected to provide evidence based policy guidelines for policy makers. The analysis includes managerial and technical dimensions for the screening of blood and blood products in the individual facilities with focus on TTI's. The analysis emanating from the national baseline survey would help enable the key stakeholders to have a comprehensive view of all aspects of the existing national blood transfusion situation in general and TTI's in particular. The key findings and information gathered from the national baseline survey would help advocate and develop strategies to strengthen the Safe Blood Transfusion Programme to prevent the spread of TTI's and improve the quality and safety of blood transfusion in Pakistan.

A detailed report of the recommendations to improve the blood screening system in specific and the overall blood transfusion services in general in the country, will be submitted to the Ministry of National Health Services.

\section{Funding}

The baseline survey was conducted under the overall management and guidance of the Safe Blood Transfusion Programme, Pakistan and funded by the OPEC Fund for International Development (OFID) and World Health Organization (WHO).

\section{Acknowledgements}

Provincial Blood Transfusion Programmes, private sector Blood Centers and Safe Blood Transfusion Programme (SBTP) staff.

\section{References}

1. http://www.psh.org.pk.

2. Waheed U, Khan H, Satti HS, Ansari A, Malik MA, et al. (2012) Transfusion Transmitted Infections among Blood Donors of a Teaching Hospital in Islamabad. Ann. Pak. Inst. Med. Sci. 8: 236-239.

3. Waheed U, Zaheer HA, Naseem L, Hasan K (2009) Study of Hepatitis B and $\mathrm{C}$ virus seropositivity in healthy blood donors. Ann. Pak. Inst. Med. Sci. 5: 233-236.

4. http://www.nacp.gov.pk/library/reports/Surveillance\%20\&\%20Research/ Final\%20Report\%20of\%20Sosec\%20on\%20Safe\%20Blood.pdf.

5. Zaheer HA, Waheed U (2014) Legislative Reforms of the Blood Transfusion System in Pakistan. Transfus Med 24: 117-119.

6. Nishtar S, Mehboob AB (2011) Pakistan prepares to abolish Ministry of Health. Lancet, 378: 648-649. 
Citation: Zaheer HA, Waheed U (2015) National Baseline Survey on Monitoring and Evaluation of Blood Screening Systems in Pakistan. J Blood Disorders Transf 6: 265. doi:10.4172/2155-9864.1000265

Page 5 of 5

7. Pakistan Medical Research Council (2008) Prevalence of Hepatitis B and C in Pakistan. 2008. Pakistan Medical Research Council, Ministry of Health, Government of Pakistan.

8. http://www.who.int/bloodsafety/ScreeningDonated BloodforTransfusion.pdf.
9. Ayyoubi MT, Konstenius T, McCullough JC, Eastlund T, Clay M, et al. (2010) Status of blood banking and the blood supply in Afghanistan. Transfusion 50: 566-574. 